\title{
Kajian Kapasitas J alan dan Derajat Kejenuhan Lalu-Lintas di J alan Ahmad Yani Surabaya
}

\author{
Dunat Indratmo \\ Dosen D3 Teknik Sipil FTSP-ITS \\ email: dunat@ce.its.ac.id
}

\begin{abstract}
ABSTRAK
Jumlah kendaraan bermotor di kota Surabaya dari hari ke hari semakin meningkat, sehingga menimbulkan kepadatan dan kemacetan lalu-lintas. Kemacetan dan kepadatan lalu-lintas, merupakan gambaran nyata bahwa kapasitas jalan telah terlampaui dan derajat kejenuhan (DS) semakin meningkat, seperti halnya Jl. Ahmad Yani Surabaya sebagai jalan Arteri Primer yang menghubungkan Surabaya dan Sidoarjo. Pengkajian kapasitas dan derajat kejenuhan, diharapkan bermanfaat bagi para pengambil kebijakan dibidang manajemen transportasi dan rekayasa lalu-lintas. Data primer arus kendaraan bermotor yang lewat di jalan Ahmad Yani berupa Sepeda Motor (SM), Mobil Penumpang Pribadi (MPP), Mobil Penumpang Umum (MPU), Bis dan Truk, diperoleh dengan cara menghitung di suatu titik oleh 6 (enam) Observer menggunakan Traffic Counter, dicatat selama 3 (tiga) hari @ 8 (delapan) jam dengan mempertimbangkan jam-jam puncak (peak hours), serta karakteristik hari-hari kerja. Pengkajian menggunakan metode Manual Kapasitas Jalan Indonesia 1997 dan software KAJ I 2001. Hasil pengkajian menunjukkan, bahwa kapasitas Jl. Ahmad Yani saat ini (tahun 2006) adalah $4.428 \mathrm{smp} /$ jam untuk arah Sidoarjo ke Surabaya pada kondisi lebar perkerasan rata-rata 10,25 meter, arus kendaraan rata-rata yang lewat $6.506 \mathrm{smp} / \mathrm{jam}$, dengan $\mathrm{DS}=1,469$ dan diprediksikan mencapai 1,715 pada tahun 2010. Sedangkan untuk arah Surabaya ke Sidoarjo pada kondisi lebar perkerasan rata-rata 9,70 meter kapasitasnya adalah $3.954 \mathrm{smp} / \mathrm{jam}$, arus kendaraan rata-rata yang lewat $5.835 \mathrm{smp} / \mathrm{jam}$, dengan DS =1,475 dan diprediksikan mencapai 1,727 pada tahun 2010.
\end{abstract}

Kata kunci : Kapasitas J alan, Derajat Kejenuhan

\section{PENDAHULUAN}

Pertambahan jumlah kendaraan bermotor di kota-kota besar di Indonesia termasuk Surabaya, cenderung meningkat sehingga semakin berdampak terhadap peningkatan kemacetan lalu-lintas dan terlampauinya kapasitas jalan, serta peningkatan derajat kej enuhan Ialu-lintas. Kemacetan Ialu-lintas merupakan cerminan padatnya lalu-lintas dan tingginya tingkat kejenuhan, serta terjadi kecepatan kendaraan yang relatif menurun dibandingkan dengan kecepatan yang direncanakan bagi setiap fungsi dan peran jalan. Penelitian ini mengkaji kapasitas dan Derajat Kejenuhan atau Degree of Saturation (DS) Ialu-lintas di J alan Ahmad Yani saat sekarang, maupun prediksi pada masa mendatang. Jalan Ahmad Yani Surabaya merupakan jalan Arteri Primer dua arah (dengan pemisah arah) sebagai penghubung kota Surabaya dan Sidoarjo, dan masing-masing arah terdiri dari 3 (tiga) lajur. Sesuai dengan Peraturan Pemerintah
Nomor 26 Tahun 1985 tentang Jalan, kecepatan rencana pada J alan Arteri Primer seharusnya dapat mencapai $60 \mathrm{~km} / \mathrm{jam}$. Hasil kajian ini diharapkan dapat dimanfaatkan sebagai bahan pertimbangan, oleh para pengambil kebijakan dibidang transportasi dalam hal manajemen dan rekayasa lalu-lintas.

\section{TINJ AUAN PUSTAKA}

Arus lalu-lintas (Traffic Flow), adalah pergerakan sejumlah kendaraan yang terdiri dari berbagai jenis, disepanjang ruas/ segmen jalan. Besaran Arus Ialu-lintas yang biasa disingkat dengan istilah Flow $(\mathbf{Q})$, menyatakan jumlah kendaraan yang dihitung pada titik ruas jalan dalam satuan waktu, yaitu kendaraan per jam dengan singkatan "kend/jam", atau dalam satuan mobil penumpang per jam dengan singkatan "smp/ jam". 
Kecepatan lalu-lintas (Traffic Speed), adalah kecepatan rata-rata kendaraan yang diukur di suatu titik pada ruas/ segmen jalan dalam periode waktu tertentu. Kecepatan rata-rata kendaraan tersebut (V), dinyatakan dalam satuan panjang per satuan waktu, yaitu dalam kilometer per jam dengan singkatan "km/ jam".

Kepadatan Ialu-lintas (Traffic Density), adalah jumlah kendaraan yang lewat pada suatu ruas jalan dalam satuan panjang jalan tertentu. Kepadatan Ialu - lintas atau Densitas (K), dinyatakan dalam jumlah kendaraan yang lewat sepanjang satu kilometer (Kendaraan/ Km).

Satuan Mobil Penumpang (SMP), adalah satuan yang dipergunakan untuk menyatakan jumlah dari berbagai jenis kendaraan, yang telah dikonversikan dengan angka konversi tertentu terhadap jenis mobil penumpang.

\section{Korelasi Kecepatan-Kepadatan}

Kecepatan Ialu-lintas berkorelasi terhadap kepadatan Ialu-lintas secara linear atau mendekati linear (seperti terlihat pada Gambar 2.1.). Pada kecepatan sebesar $V_{1}$ terjadi kepadatan $K_{1}$, bila kecepatan menurun menjadi $V_{2}$, maka kepadatan bertambah menjadi $\mathrm{K}_{2}$.

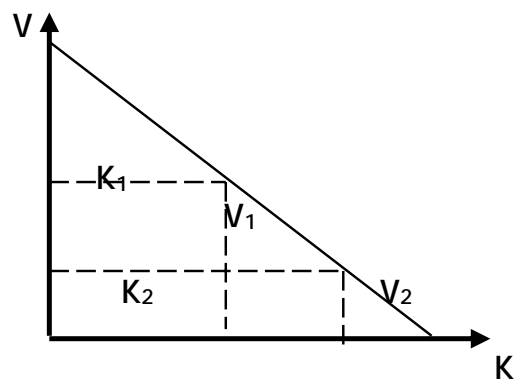

Gambar 2.1. Korelasi Kecepatan dan Kepadatan Lalu-Lintas

\section{Korelasi Arus-Kepadatan}

Arus Ialu-lintas (Q) berkorelasi terhadap kepadatan lalu-lintas (K) secara parabolik. Arus Ialu-lintas semakin bertambah, maka akan meningkat kepadatannya. Bila arus lalu-lintas mencapai optimum (sesuai kapasitas jalan), akan dicapai $50 \%$ kepadatan. Pertambahan jumlah kendaraan selanjutnya, menyebabkan arus lalu-lintas menjadi menurun dan kepadatan semakin bertambah. (Gambar 2.2.)

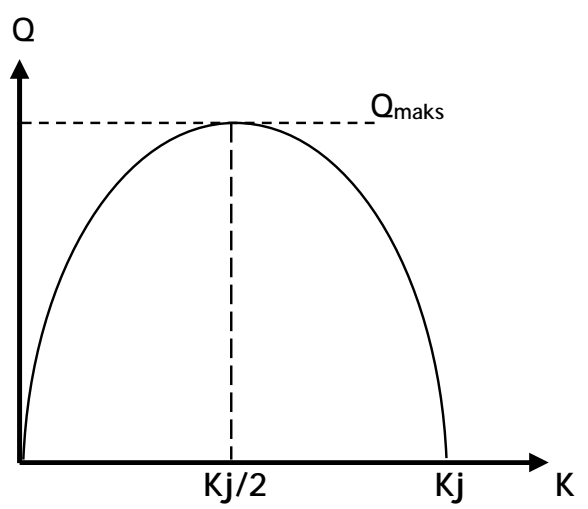

Gambar 2.2. Korelasi Arus dan Kepadatan Lalu-Lintas

Korelasi Kecepatan-Arus

Jika arus lalu-lintas meningkat, kecepatan cenderung menurun secara perlahan. Jika arus mendekati kapasitas, penurunan kecepatan semakin besar. Arus maksimum didapat pada saat kapasitas dicapai. Apabila kondisi tersebut terus menerus dipaksakan untuk mendapatkan arus yang melebihi kapasitas, maka akan terjadi kondisi yang tidak stabil dan malah tercipta arus yang lebih kecil dengan kecepatan yang lebih rendah (Gambar 2.3.).

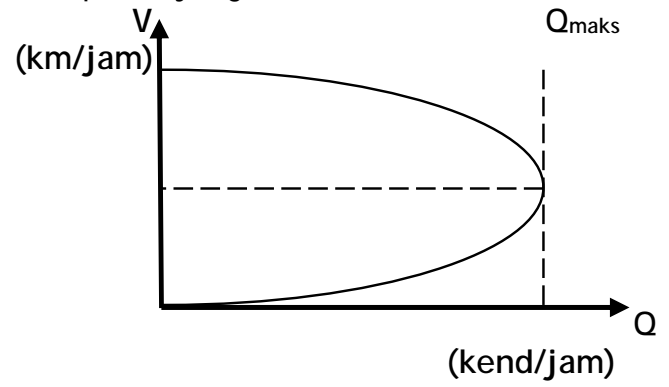

Gambar 2.3. Korelasi Kecepatan dan Arus Lalu-Lintas

Arus dan kecepatan lalu-lintas yang berkorelasi terhadap kepadatan Ialu-lintas (Kadiyali, 1983 ), dapat dinyatakan hubungan seperti berikut :

$$
\mathbf{K}=\mathbf{Q} / \mathbf{V}
$$

Kepadatan Ialu-lintas akan semakin besar, bila kecepatan kendaraan yang lewat semakin rendah dan atau arus lalu-lintasnya semakin besar.

\section{Derajat kejenuhan (DS)}

Derajat Kejenuhan atau Degree of Saturation, adalah rasio arus lalu-lintas 
(smp/jam) terhadap kapasitas (smp/jam) pada bagian jalan tertentu.

Rumus-rumus yang digunakan dalam perhitungan Derajat kejenuhan (DS) sesuai dengan Manual Kapasitas Jalan Indonesia (MKJ I) 1997, adalah :

$$
\begin{gathered}
D S=\frac{Q}{C} \\
C=C o \times F C w \times F C s p \times F C s f
\end{gathered}
$$

\section{METODOLOGI}

\section{Sistematika Pengkaj ian}

Sistematika pengkajian yang diterapkan, diuraikan seperti bagan alir pada gambar 3.1. berikut.

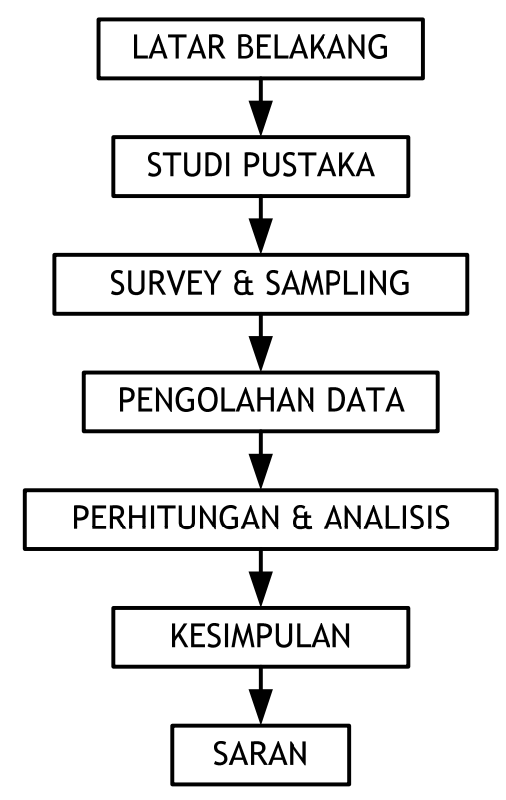

\section{Gambar 3.1. Bagan Alir Sistematika Pengkajian}

\section{Penetapan Lokasi Sampling}

Penetapan lokasi sampling di suatu titik pada segmen jalan daerah penelitian, didasarkan atas pertimbangan :

- Tidak adanya pengaruh langsung dari antrian kendaraan, akibat kedekatannya dengan pertemuan jalan atau persimpangan jalan (simpang bersignal maupun yang tidak bersignal).
- Tidak adanya pengaruh langsung dari antrian kendaraan akibat adanya tempat pemutaran arah (U-Turn).

- Kestabilan arus lalu-lintas sepanjang waktu, atau seminim mungkin terjadinya kemacetan total.

Sedangkan waktu sampling ditetapkan dengan pertimbangan seperti berikut :

- Karakteristik lalu-lintas pada hari-hari tertentu, seperti hari Senin adalah hari kerja pertama setiap minggu, maka kepadatan Ialu-lintasnya relatif tinggi. Hari Selasa, Rabu dan Kamis adalah hari kerja yang karakteristik lalu-lintasnya relatif sama. Sedangkan hari Jum'at adalah hari kerja terakhir setiap minggu, maka kepadatan Ialu-lintasnya relatif tinggi.

- Karakteristik lalu-lintas pada jam-jam sibuk (peak hours), hingga jam-jam sepi (low hours), agar diperoleh variasi data yang tersebar acak atau merata. J am sibuk lalu-lintas terjadi pada jam keberangkatan bekerja dan jam keberangkatan siswa ke sekolah(06.00 - 09.00), jam kepulangan dari bekerja (15.00 - 17.00). J am sepi lalulintas terjadi pada saat tertentu, misalnya J am 12.00 - 13.00 hari J um' at.

- Sampling data arus kendaraan ditentukan pada hari Senin jam 06.00-14.00, hari Rabu jam 11.00-20.00 dan hari Jum'at jam 09.00-17.00. Sampling hari Rabu merupakan representasi dari karakteristik hari Selasa, Rabu dan Kamis.

(Komputasi menggunakan Software KAJ I 2001)

\section{HASIL DAN PEMBAHASAN}

Kondisi jalan Ahmad Yani saat ini mempunyai lebar perkerasan 10,25 m (3 lajur) dengan kapasitas $4.428 \mathrm{smp} / \mathrm{jam}$ untuk arah Sidoarjo ke Surabaya, dan 9,70 m (3 lajur) dengan kapasitas $3.954 \mathrm{smp} / \mathrm{jam}$ untuk arah Surabaya ke Sidoarjo Karakteristik arus kendaraan pada setiap hari Senin dari arah Sidoarjo ke Surabaya, pada umumnya menunjukkan kepadatan yang tinggi pada pagi hari antara jam 07.0010.00, terutama jenis kendaraan Sepeda Motor (SM). Hari Senin merupakan hari kerja pertama setiap minggu, sehingga seluruh warga masyarakat memulai aktivitasnya setelah berlibur akhir pekan atau refreshing. Padatnya lalu-lintas pada jamjam pagi tersebut dikarenakan banyaknya pegawai dan karyawan yang berangkat 
menuju ke kantornya, serta para pelajar yang menuju ke sekolahnya di kota surabaya, tetapi tempat tinggalnya (bermukim) di kota Sidoarjo dan sekitarnya dalam wilayah Kabupaten Sidoarjo, maupun di wilayah Surabaya Selatan. Seperti halnya hasil survey pada hari Senin 01 Mei 2006 antara jam 06.00-14.00, jumlah kendaraan SM arah Sidoarjo ke Surabaya menunj ukkan angka $9.702 \mathrm{kend} / \mathrm{jam}$ pada jam 07.0008.00, sedangkan Mobil Penumpang Pribadi (MPP) sejumlah $2.557 \mathrm{kend} / \mathrm{jam}$, Mobil Penumpang Umum (MPU) sejumlah 400 kend/jam, BIS sejumlah $76 \mathrm{kend} / \mathrm{jam}$ dan TRUK sejumlah $49 \mathrm{kend} / \mathrm{jam}$. Hasil perhitungan arus kendaraan tertinggi terjadi pada jam 07.00-08.00 menunjukkan sejumlah $7.213 \mathrm{smp} / \mathrm{jam}$ dan angka DS-nya 1,629 (seharusnya tidak melebihi 1,0), sehingga hal ini menunjukkan rendahnya kecepatan kendaraan yang lewat, atau terjadi kepadatan yang tinggi, setidaktidaknya padat merambat. Angka DS terendah terjadi pada jam 11.00-12.00, yaitu sebesar 1,415. Selanjutnya fluktuasi perubahan angka DS dari jam 06.00-14.00, seperti terlihat pada Gambar 4.1. berikut.

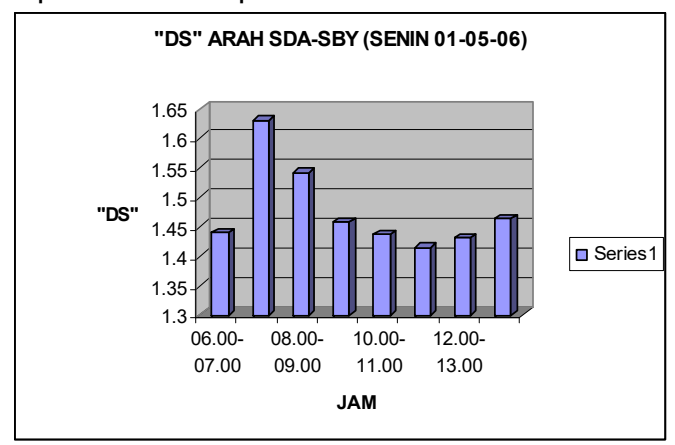

Gambar 4.1. DS Arah Sda-Sby Hari Senin

Arus kendaraan pada setiap hari Senin antara jam 06.00-14.00 dari arah Surabaya ke Sidoarjo, juga cukup padat walaupun tidak sepadat arah dari Sidoarjo ke Surabaya. Arus kendaraan pada hari Senin 01 Mei 2006 antara jam 07.00-08.00 menunjukkan sejumlah $5.267 \mathrm{smp} / \mathrm{jam}$, dan angka DS-nya 1,332 (seharusnya tidak melebihi 1,0$)$. Arus kendaraan yang terbesar sejumlah $6.089 \mathrm{smp} / \mathrm{jam}$, terjadi antara jam 13.00-14.00 dan angka DS-nya 1,540. Sedangkan arus kendaraan terendah pada hari Senin 01 Mei 2006 untuk arah Surabaya ke Sidoarjo, terjadi pada jam 06.00-07.00 sejumlah $4.749 \mathrm{smp} / \mathrm{jam}$ dan DS-nya mencapai angka 1,201 (masih melebihi 1,0). Selanjutnya fluktuasi perubahan angka DS dari jam 06.00-14.00, seperti terlihat pada Gambar 4.2. berikut.

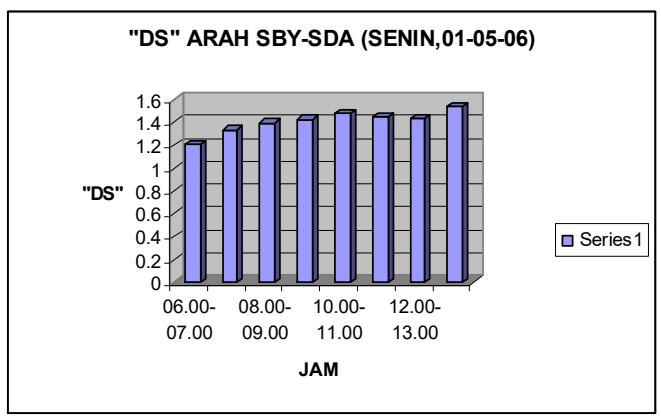

Gambar 4.2. DS Arah Sby-Sda Hari Senin

Hari Rabu merupakan hari kerja biasa, rutinitasnya relatif sama dengan hari Selasa dan Kamis. Oleh karenanya, karakteristik arus kendaraan juga relatif sama, angka kepadatan yang tinggi terjadi pada jam berangkat kantor (pagi) dan jam pulang kantor (sore). Arus kendaraan tertinggi untuk arah Sidoarjo ke Surabaya hari Rabu 03 Mei 2006, terjadi pada jam 16.00-17.00 sejumlah $6.956 \mathrm{smp} / \mathrm{jam}$ dan DS-nya 1,571 (seharusnya tidak melebihi 1,0). Sedangkan arus kendaraan terendah pada hari Rabu 03 Mei 2006 untuk arah Sidoarjo ke Surabaya, terjadi pada jam 12.00-13.00 sejumlah $5.969 \mathrm{smp} / \mathrm{jam}$ dan DS-nya mencapai angka 1,348 (masih melebihi 1,0). Selanjutnya fluktuasi perubahan angka DS dari jam 11.00-20.00, seperti terlihat pada Gambar 4.3. berikut.

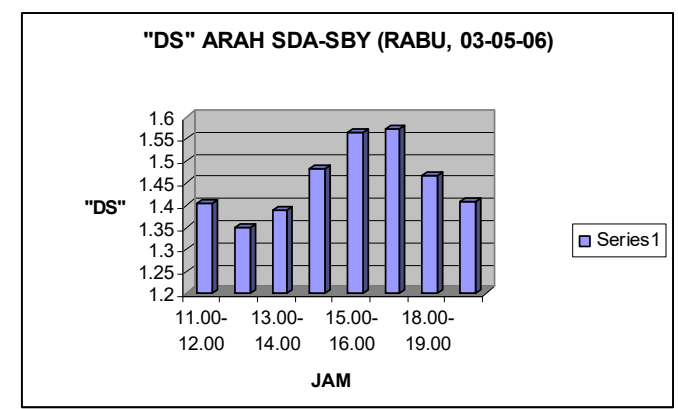

Gambar 4.3. DS Arah Sda-Sby Hari Rabu

Arus kendaraan tertinggi pada hari Rabu 03 Mei 2006 untuk arah Surabaya ke Sidoarjo, terjadi pada jam 16.00-17.00 sejumlah $6.959 \mathrm{smp} / \mathrm{jam}$ dan DS-nya 1,760 (seharusnya tidak melebihi 1,0 ). Pada jam 
tersebut, merupakan saatnya para pegawai pulang dari kantor menuju ke rumahnya di kawasan Sidoarjo dan sekitarnya. Sedangkan arus kendaraan yang terendah, terjadi pada jam 12.00-13.00 sejumlah $5.508 \mathrm{smp} / \mathrm{jam}$ dan DS-nya mencapai angka 1,393 (masih melebihi 1,0). Selanjutnya fluktuasi perubahan angka DS dari jam 11.00-20.00, seperti terlihat pada Gambar 4.4. berikut.

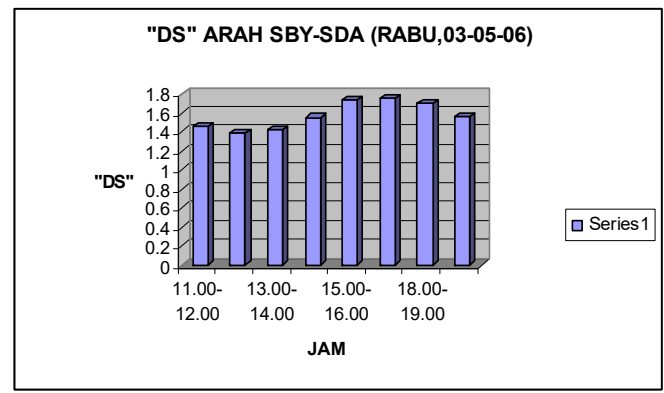

\section{Gambar 4.4. DS Arah Sby-Sda Hari Rabu}

Hari J um'at pada umumnya merupakan hari kerja terakhir selama seminggu bagi Pegawai Negeri dan sebagian besar karyawan kantor swasta, sehingga banyak warga masyarakat yang mengadakan perjalanan ke luar kota setelah jam selesai kantor, untuk refreshing atau mudik bagi pegawai/karyawan yang berdomisili di luar kota Surabaya. Karakteristik arus kendaraan setiap hari Jum'at sore antara jam 15.0017.00, pada umumnya meningkat sehingga lebih sering terjadi kemacetan. Begitu pula pada pagi awal jam kerja, juga tidak berbeda dengan hari kerja lainnya. Sedangkan pada hari Jum'at siang antara jam 11.00-13.00 terjadi penurunan arus kendaraan bagi kedua arah, dikarenakan sebagian besar masyarakat melaksanakan Ibadah sholat Jum'at di Masjid-Masjid. Arus kendaraan tertinggi pada hari J um' at $05 \mathrm{Mei}$ 2006 untuk arah Sidoarjo ke Surabaya, terjadi pada jam 16.00-17.00 sejumlah $7.598 \mathrm{smp} /$ jam dan DS-nya mencapai angka 1,716 (seharusnya tidak melebihi 1,0). Sedangkan arus kendaraan yang terendah, terjadi pada jam 12.00-13.00 sejumlah $5.500 \mathrm{smp} / \mathrm{jam}$ dan DS-nya mencapai angka 1,242 (masih melebihi 1,0). Selanjutnya fluktuasi perubahan angka DS dari jam 09.00-17.00, seperti terlihat pada Gambar 4.5. berikut.

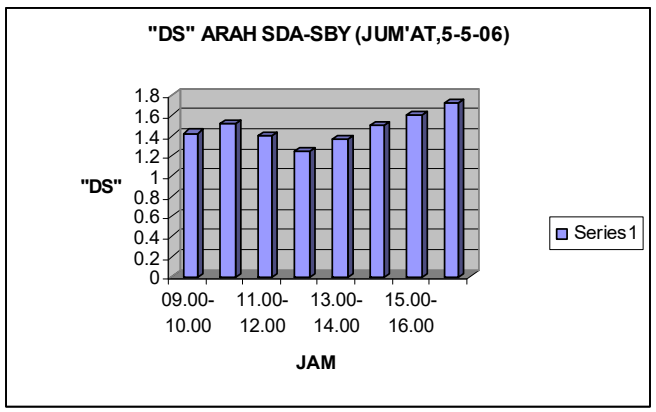

Gambar 4.5. DS Arah Sda-Sby Hari J um' at

Arus kendaraan tertinggi pada hari J um'at 05 Mei 2006 untuk arah Surabaya ke Sidoarjo, terjadi pada jam 16.00-17.00 sejumlah $6.773 \mathrm{smp} / \mathrm{jam}$ dan DS-nya 1,713 (seharusnya tidak melebihi 1,0). Pada jam tersebut, merupakan saatnya para pegawai pulang dari kantor menuju ke rumahnya di kawasan Sidoarjo dan sekitarnya, serta warga masyarakat yang menuj u ke luar kota. Sedangkan arus kendaraan yang terendah, terjadi pada jam 12.00-13.00 sejumlah 4.887 smp/ jam dan DS-nya mencapai angka 1,236 (masih melebihi 1,0). Selanjutnya fluktuasi perubahan angka DS dari jam 09.00-17.00, seperti pada Gambar 4.6. berikut.

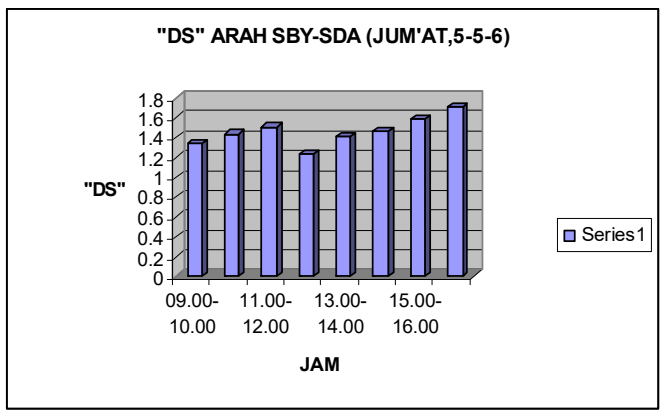

Gambar 4.6. DS Arah Sby-Sda Hari J um'at

Hasil perhitungan rerata dari kondisi arus kendaraan maupun derajat kejenuhan tersebut diatas, dapat diprediksikan bahwa :

- Arah Sidoarjo ke Surabaya, arus kendaraan rata-rata saat ini (tahun 2006) adalah $6.505 \mathrm{smp} / \mathrm{jam}$, dengan rincian SM $7.928 \mathrm{kend} / \mathrm{jam}$, MPP 2.396, MPU 455 kend/jam, BIS 78 kend/jam dan TRUK 83 kend/jam, sedangkan DS-nya menunjukkan angka 1,467. Bila dalam beberapa tahun mendatang tidak ada solusi penambahan kapasitas jalan, dan diperhitungkan pertumbuhan kendaraan 
rata-rata per tahun untuk SM 5,5\% MPP 3 $\%$ MPU 0,75\% BIS 0,5 \% dan TRUK 1, $25 \%$ maka DS pada tahun 2010 diprediksikan mencapai 1,715 dan pada tahun 2016 akan mencapai 2,180. Prediksi DS jalan Ahmad Yani selanjutnya, seperti terlihat pada Tabel 4.1.

- Arah Surabaya ke Sidoarjo, arus kendaraan rata-rata saat ini (tahun 2006) adalah $5.835 \mathrm{smp} / \mathrm{jam}$, dengan rincian SM $7.298 \mathrm{kend} / \mathrm{jam}, \mathrm{MPP} 2.151$, MPU 408 kend/jam, BIS 63 kend/ jam dan TRUK 56 kend/jam, sedangkan DS-nya menunjukkan angka 1,475. Bila dalam beberapa tahun mendatang tidak ada solusi penambahan kapasitas jalan, dan diperhitungkan pertumbuhan kendaraan rata-rata per tahun untuk SM 5,5\% MPP 3 $\%$ MPU 0,75\% BIS 0,5 \% dan TRUK 1,25\% maka DS pada tahun 2010 diprediksikan mencapai 1,727 dan pada tahun 2016 akan mencapai 2,202. Prediksi DS jalan Ahmad Yani selanjutnya, seperti terlihat pada Tabel 4.1.

Tabel 4.1. Prediksi DS J I. Ahmad Yani

\begin{tabular}{|c|c|c|}
\hline \multirow{2}{*}{ TAHUN } & \multicolumn{2}{|c|}{ DS J L. AHMAD YANI } \\
\cline { 2 - 3 } & ARAH SDA-SBY & ARAH SBY-SDA \\
\hline 2006 & 1.469 & 1.475 \\
\hline 2007 & 1.526 & 1.534 \\
\hline 2008 & 1.586 & 1.595 \\
\hline 2009 & 1.649 & 1.659 \\
\hline 2010 & 1.715 & 1.727 \\
\hline 2011 & 1.784 & 1.797 \\
\hline 2012 & 1.856 & 1.870 \\
\hline 2013 & 1.932 & 1.948 \\
\hline 2014 & 2.011 & 2.028 \\
\hline 2015 & 2.094 & 2.113 \\
\hline 2016 & 2.180 & 2.202 \\
\hline
\end{tabular}

\section{KESIMPULAN DAN SARAN}

\subsection{Kesimpulan}

1. Kapasitas jalan Ahmad Yani saat ini (tahun 2006), arah Sidoarjo ke Surabaya adalah $6.505 \mathrm{smp} / \mathrm{jam}$ dengan lebar perkerasan 10,25 meter (3 lajur), sedangkan arah Surabaya ke Sidoarjo adalah $5.835 \mathrm{smp} / \mathrm{jam}$ dengan lebar perkerasan 9,70 meter (3 lajur).

2. Kondisi arus lalu-lintas di jalan Ahmad Yani saat ini (tahun 2006), baik arah Sidoarjo ke Surabaya maupun arah Surabaya ke Sidoarjo, sering terjadi kemacetan terutama pada jam-jam puncak dan hari-hari kerja, dengan angka rata-rata parameter Derajat Kejenuhannya atau Degree of Saturation (DS) masing-masing arah, berturut-turut sebesar 1,469 dan 1,475 yang telah jauh melampaui ambang batas ( $D S=1,0$ ).

3. Bila dalam beberapa tahun mendatang tidak ada solusi penambahan kapasitas jalan, maka DS pada tahun 2010 untuk arah Sidoarjo ke Surabaya diprediksikan mencapai 1,715 dan pada tahun 2016 akan mencapai 2,180. Sedangkan DS jalan Ahmad Yani pada tahun 2010 arah Surabaya ke Sidoarjo diprediksikan mencapai 1,727 dan pada tahun 2016 akan mencapai 2,202.

\subsection{Saran}

1. Bila belum ada alternatif lain yang lebih efektif untuk mengatasi kemacetan Ialulintas di jalan Ahmad Yani Surabaya, maka disarankan segera menambah kapasitas jalan, dengan merealisasikan pembangunan Frontage Road paling lambat pada tahun 2008. Bila tidak ada penanganan sama sekali guna mengatasi kemacetan Ialu-lintas sampai dengan tahun 2008, maka kemacetan lalu-lintas akan semakin meningkat, dengan prediksi DS masing-masing arah sebesar 1,586 dan 1,595 pada tahun 2008.

2. Perlu dilakukan pengkajian secara komprehensif, terhadap alternatif rencana pembangunan jalan bebas hambatan (Tol Tengah) yang direncanakan melewati segmen jalan Ahmad Yani, sehingga diketahui secara kuantitatif seberapa signifikansinya dalam mengatasi kemacetan Ialu-lintas di jalan Ahmad Yani.

3. Perlu dilakukan pengkajian secara komprehensif, terhadap alternatif rencana pembangunan jalan lingkar luar (Outer Ring Road) timur, sehingga diketahui secara kuantitatif seberapa signifikansinya dalam mengatasi kemacetan lalu-lintas di jalan Ahmad Yani dan segmen jalan lainnya di dalam kota Surabaya.

\section{DAFTAR NOTASI}
K : Kepadatan Ialu-lintas (kend/ $\mathrm{km}$ )
$\mathrm{V}$ : Kecepatan rata-rata kendaraan
$(\mathrm{km} / \mathrm{jam})$
DS : Derajat kejenuhan
Q : Arus lalu lintas (smp/ jam atau 


$$
\begin{array}{ll}
\text { C } & \begin{array}{l}
\text { kend/jam) } \\
\text { Kapasitas jalan (smp/jam) } \\
\text { FCw }: \text { Kapasitas dasar (smp/jam) }
\end{array} \\
\text { FCsp : } \begin{array}{l}
\text { Faktor penyesuaian kapasitas } \\
\text { akibat lebar jalur lalu lintas } \\
\text { akibat pemisahan arah } \\
\text { FCsf : }
\end{array} & \begin{array}{l}
\text { Faktor penyesuaian kapasitas } \\
\text { akibat hambatan samping }
\end{array}
\end{array}
$$

\section{DAFTAR ACUAN}

Beach, David P. dan Alvager, Torsten K.E, 1992, "Handbook for Scientific and Technical Research", Prentice HallEnglewood Cliffs, New J ersey.

Departemen Pekerjaan Umum, 1997,

"Manual Kapasitas Jalan Indonesia 1997", Direktorat J enderal Bina Marga.
Kadiyali, L.R, 1983, “Traffic Engineering and Transport Planning", Khana Publishers-Delhi.

Morlok, Edward K, 1988, "Introduction To Transportation Engineering and Planning", Mc Graw-Hill, Inc.

Oglesby, Clarkson H. and Hicks, R, 1982, "Highway Engineering", Fourth Edition, J ohn Wiley \& Sons, Inc.

Sekretaris Negara, 1985, "Peraturan Pemerintah Republik Indonesia Nomor 26 Tahun 1985", Sekretariat Negara.

Tamin, 0.Z, 2003, "Perencanaan \& Pemodelan Transportasi", Penerbit ITB Bandung.

Sekretaris Negara, 2004, Undang-Undang RI Nomor 38 Tahun 2004 tentang Jalan, Sekretariat Negara. 